\title{
Analysis of Metallurgical Raw Materials and Environmental Protection
}

\author{
Dongxing $\mathrm{HUO}^{1, \text { a }}$, Jinglong LIANG ${ }^{1, b}$ and $\mathrm{Yu} \mathrm{YANG}^{1, \mathrm{c}}$ \\ ${ }^{1}$ College of Metallurgy and Energy, North China University of Science and \\ Technology, Tangshan Hebei 063009, China \\ a1158894892@qq.com, ${ }^{\mathrm{b}} \mathrm{lj} \mid @$ ncst.edu.cn, ${ }^{\mathrm{c}} 1016737925 @ q q . c o m$
}

Key words:raw material;pollute;relation

Abstract: In the process of smelting metal will produce a lot of environmental pollution by gas and waste residue, here for metallurgical raw materials and direct or indirect relationship between the environment for analysis.

\section{Introduction}

Metallurgical process is a conversion process of raw materials, and we want to get and refine, remove the material properties, through all kinds of auxiliary means to obtain a certain physical and chemical properties can be used by people. ${ }^{[1]}$ This process is bound to produce a lot of material that is not needed. May be gas, may be solid, it may be difficult to remedy the impact of the environment. In this government to promote sustainable development, people enjoy a harmonious and healthy life of the times, environmental protection is imperative. Here we explore the link between the selection of raw materials and environmental pollution. To provide a new idea for environmental protection.

\section{Metallurgical raw materials}

Raw materials for steel making use of raw materials, auxiliary materials and various iron alloys. The main use of BOF steelmaking raw materials for molten iron and scrap (iron). Steelmaking raw materials usually refers to the slagging agent (lime, fluorite, dolomite, synthetic slagging agent), (iron ore, iron oxide, sintered ore, pellets) coolant, carburant and oxygen, nitrogen, argon and other. Steel commonly used iron alloy ferromanganese, ferrosilicon, silicon manganese alloy with calcium alloy, metal,aluminum etc..

Raw material is the material basis of steel making. The quality of raw material has a direct influence on the quality of steel making process and steel. Domestic and foreign large production practice has proved that the use of fine material and raw material standardization, is to achieve smelting process automation, improve the technical and economic indicators, improve the economic benefits of the important way. According to the refining of steel, operation process and equipment level of reasonable selection and collocation) I material can achieve low cost and high quality output. Hot metal is the main raw material for steel making, which is generally accounted for $70 \%$ to $100 \%$ of the total load ${ }^{[2]}$. The chemical and physical heat of hot metal is the main source of BOF steelmaking. Therefore, the chemical composition and temperature of hot metal in the furnace must be required. The temperature of the hot metal is a sign that the amount of heat is brought into the converter, and the hot metal is about $50 \%$ of the heat in the converter. High temperature of hot metal will be beneficial to the automatic control of the stable operation and converter. Molten iron temperature is too low, the elements influence the oxidation process and molten pool temperature lifting speed, not conducive to the slag and impurity removal, prone to spray. Therefore, China's 
steel specification requirements into the furnace hot metal temperature should be greater than 1250 , and to be relatively stable. Usually blast furnace tapping temperature in 1350 to 1450 DEG C, due to the hot metal in transportation and to be installed to heat loss in the process, so the best use of torpedo car or mixer furnace of hot metal supply, in the transport process should adding covering agent heat preservation, in order to reduce the hot metal cooling.

Silicon (Si) (Mn) and P (S) carbon (C) are the main elements in the hot metal, they are the whole process, the results of the waste gas, waste residue has a great impact.

\section{Raw material handling}

Silicon is one of the elements in the process of converter steelmaking. The high content of silicon, the converter will increase the heat, can increase the scrap ratio. The data indicate that, for each additional $0.1 \% \mathrm{wSi}$ in molten iron, scrap ratio increasing by about $1.3 \%$. High silicon content of hot metal, slag volume increase, is conducive to the removal of phosphorus and sulfur. But silicon content is too high will make the slag and increase consumption, easy to cause splash, metal yield decreased. Si content high $\mathrm{SiO} 2$ in the slag content is too high, will also contribute to the erosion of furnace lining, and the influence of the lime residue rate, prolong the time of blowing.

Manganese content in molten iron high on smelting favorable, $\mathrm{MnO}$ is formed in the early stage of blowing, can accelerate lime dissolution, promote the initial slag early formation, improve the fluidity of the slag, for desulfurization and improve the service life of the lining ${ }^{[3]}$. High manganese content in molten iron, high manganese steel at the end of $\mathrm{Yu}$, can reduce the amount of manganese to improve the purity of molten steel, etc.. The ratio of to $\mathrm{wMn} / \mathrm{wsi}$ is $0.8 \sim 1$, which is used for low manganese iron.

Phosphorus is high heating elements, most of the steel is to remove the harmful elements. Therefore, requirement phosphorus hot metal content the lower the better, general requirements for hot metal wP is less than or equal to $0.20 \%$; phosphorus in hot metal content is low, the operation of converter process is simplified and to improve the technical and economic indicators.

Technical specification for steel in China requires furnace $\mathrm{wS}=0.05 \%$. The sulfur content in molten iron smelting high-quality low sulfur steel is lower, even the pure steel requirements of molten iron is less than or equal to $0.005 \% \mathrm{wS}$. Therefore, it is necessary to reduce the sulfur content in the hot metal in the furnace.

And some other raw materials. They have a great influence on the gas composition, such as:lime is the main steelmaking slag material, with $\mathrm{P}$ removal, $\mathrm{S}$ removal ability, is also the largest amount. The quality of blowing process, has an important effect on product quality and service life etc.. Therefore, the content of $\mathrm{CaO}$ is high, the content of $\mathrm{Si0} 2$ and the content of $\mathrm{S}$ is low, the rate of lime is low, the activity is high, and it is suitable for the block degree. Besides, it should be clean, dry and fresh.

Fluorite is flux, its main component is CaF2. The melting point of pure $\mathrm{S}$ is 1418 , and fluorite contains $\mathrm{CaF} 2$ and $\mathrm{SiO} 2$, so the melting point is about 930. The melting point of $\mathrm{CaO}$ and $\mathrm{SiO} 2$ is reduced, and the $3 \mathrm{CaO} 2 \mathrm{Si0} 22 \mathrm{CaO}$, and $\mathrm{CaF} 2$ can be formed. Fast and short time of fluorite. But excessive use of fluorite will serious foam slag formation, leading to the expulsion, but also intensified the lining erosion and pollution of the environment. Therefore, we should strictly control the amount of per ton of fluorite ${ }^{[5]}$.

\section{Metallurgical waste gas}

The waste gas emission is big, the pollution is wide, the temperature is high, the composition is 
complex, the control is difficult, the dust particles are fine, and the adsorption ability is strong. Metallurgical waste gas containing a large number of toxic pollutants, such as mercury, arsenic, lead, chromium, zinc and other dust or steam and flue gas SO2, HF, HCN, CO and other toxic gases, must be dust purification, to achieve emission standards. Recycling valuable metals, improve metal recovery rate and comprehensive utilization. Some of the precious metals, precious metals, and the complex composition of the dust in the process of smelting, especially the rare metals ${ }^{[6]}$. Many metallurgical processes, such as the use of volatile method to extract mercury and antimony, slag of the smoke, and miscellaneous copper smelting, etc., the dust has been an important part of the metallurgical production. And such as roasting, flash smelting, large alumina rotary kiln technology, large capacity, high rate of soot, if there is no perfect adaptation properties of various kinds of dust, dust removal unit and the advantages of the method it is impossible to get to play and application.

\section{Domestic iron and steel industry pollution control}

Electric dust removal technology: twentieth Century 80"--90", China's rapid development of electric dust removal technology. So far, the ability to design and manufacture various types of electric dust remover has been developed, and has been exported to foreign equipment and technology. On the basis of theoretical research, some achievements have been made, such as the development of the electric field intensity and current density distribution, the plate line configuration, the pre charge technology, the wide gap between the electric dust collector, the gas quenching and tempering, pulse power supply and micro computer control, etc. some of them have reached the advanced level of the world. But the overall level of the world's advanced countries have a certain gap, such as the actual efficiency of electric dust removal efficiency is faster than the design efficiency, the important characteristics of the device is not quantitative calculation, steel consumption is large, etc..

Technology of bag type dust collector: the big bag type dust removal equipment, mainly by large negative pressure reverse blowing bag type dust collector and large pulse bag type dust collector two and gradually backward over Shu 341. The large pulse bag filter, which has a late start in China, has formed the main equipment of bag type dust removal technology ${ }^{[7]}$. Wuan Institute of independent patent series products - long bag low pressure pulse bag type dust collector through the national environmental protection products. The dust removal device has the characteristics of strong cleaning ability, low equipment resistance, small area, low running energy consumption, small maintenance workload, convenient for other bags and so on. For the five plant, Taiyuan, Anshan design 3000---16000 M2 big pulse bag filter dozens of type 361. The length of the filter bag is 6 "--8m and dust discharge concentration in the exit of the stable below $15 \mathrm{mg} / \mathrm{m} 3$, and the negative pressure reverse blowing bag type dust collector compared energy-saving $25 \%$ or so, save capital investment 30\% about. The gap with foreign advanced level is mainly manifested in the life of the filter bag, accessories, electronic performance level and steel consumption.

\section{Acknowledgements}

This work was financially supported by the National Natural Science Foundation of China (Grant No. 51474093)

\section{Reference}

[1] Shiying Shen . An Introduction to Metallurgy[M]. Metallurgy industry press, 1988. 
[2] Zhengliang Xue. An Introduction to Iron and Steel Metallurgy[M]. Metallurgical industry press, 2008.

[3] Xigu Huang. Iron and Steel Metallurgy Principles (Third Edition)[M]. Metallurgical indu stry press, 2002.

[4] Xiao Wang. Iron and Steel Metallurgy (iron parts)[M]. Metallurgical industry press, 199 1.

[5] Jiaxiang Chen. Iron and Steel Metallurgy (steel)[M]. Metallurgical industry press, 1990.

[6] Chunhua Li. Environmental Science Principle [M]. Nanjing: Nanjing University press, 2 003, (4).

[7] Wenhu Ye. An Introduction to Sustainable Development [M]. Beijing: Higher Education Press, 2003. 